\title{
ORIENTASI STRATEGI DALAM PENGUKURAN
}

\author{
Eka Zahra Solikahan, Ali Mohammad \\ Universitas Ichsan Gorontalo \\ Email: ekazahra.solikahan@gmail.com
}

\begin{abstract}
This study generally aims to explain the measurement of strategy orientation in more depth. The qualitative approach was used in this study, by applying library research methods. The data used in the form of secondary data, the scientific article to the source of the data used was elektonik data originating from Google Scholar, Emerald Insights, Sciencedirect, and SAGE. The results for measuring orientation strategy appropriate for SMEs, that are customers, competitors, low cost orientation, entrepreneurship and innovation. But generally orientation strategy can be classified into three main elements, first market orientation, which consists of knowledge, competencies and skills of employees to build good relationships with consumers, second technology orientation which includes understanding employees and managers in the use of new technologies, and the last, Orientation to reduce the cost includes the tendency to reduce costs in the form of cost leadership strategies so that it can increase market share. Third this element can interact dynamically and continuously so that they will produce competitive advantages.
\end{abstract}

\section{Keywords: literature study, strategy orientation}

\begin{abstract}
Abstrak : Penelitian ini secara umum bertujuan untuk menjelaskan mengenai pengukuran oreantasi strategi secara lebih mendalam. Pendekatan kualitatif digunakan dalam penelitan ini, dengan menerapkan metode penelitian kepustakaan (library research). Data yang digunakan berupa data sekunder, yaitu artikel ilmiah dengan sumber data yang digunakan adalah data elektonik yang bersumber dari Google Scholar, Emerald Insight, Sciencedirect, dan SAGE. Hasil yang diperoleh pengukuran orientasi strategi yang sesuai bagi UKM yakni customer, competitor, low - cost orientation, Entrepreneurship dan inovation. Namun secara umum orientasi strategi dapat dikelompokkan menjadi tiga elemen utama, yaitu: pertama market orientation, yang terdiri dari pengetahuan, kompetensi dan keterampilan karyawan untuk membangun hubungan yang baik dengan konsumen, kedua technology orientation yang meliputi dari pemahaman karyawan dan manajer dalam penggunaan teknologi baru, dan yang terakhir yaitu Orientation to reduce the cost meliputi kecenderungan untuk pengurangan biaya dalam bentuk strategi kepemimpinan biaya sehingga dapat meningkatkan pangsa pasar. Ketiga elemen ini dapat berinteraksi secara dinamis dan terus menerus sehingga akan menghasilkan keunggulan bersaing.
\end{abstract}

Kata Kunci: Orientasi strategi, Studi literatur 


\section{PENDAHULUAN}

Saat ini pemerintah sedang menggalakkan kegiatan Usaha Kecil dan Menengah (UKM) baik pada sektor modern maupun tradisional. Hal ini disebabkan UKM memiliki peran cukup besar untuk pertumbuhan ekonomi Indonesia karena sektor ini tidak terkena dampak krisis global yang melanda dunia, juga mampu menyerap tenaga kerja didalam negri sehingga UKM mampu meningkatkan pendapatan masyarakat. Oleh karena itu, sebuah strategi merupakan hal yang sangat penting bagi UKM untuk menjalankan usahanya. Karena sebuah strategi merupakan kunci kesuksesan untuk mencapai efisiensi dalam menghadapi cepatnya perubahan teknologi informasi dan persaingan yang semakin ketat.

Menurut Sarker and Palit (2015), perusahaan (UKM) dapat menggunakan strategi sebagai kunci untuk memecahkan masalah, menciptakan kemampuan baru, dan meningkatkan kinerja bisnis. Untuk mendapatkan kinerja yang lebih baik, perusahaan perlu menunjukkan konsistensi strategis internal dan sesuai dengan kebutuhan lingkungan (Pittino dan Visintin, 2009).

Beberapa penelitian terkait strategi UKM yang digunakan dalam menjalankan usaha adalah orientasi strategi seperti yang dilakukan oleh Pelham (1999), Lechner dan Gudmundsson (2012), Kumar et al. (2012), Aghajari dan Senin (2014).

Hal ini disebabkan Orientasi strategis UKM memiliki implikasi signifikan bagi manajer dalam memasuki sektor yang didominasi oleh perusahaan besar dan UKM yang mengadopsi orientasi strategis yang sesuai dapat memberikan efisiensi bagi UKM di industri tertentu, (Blumentritt and Danis, 2006).

Perkembangan orientasi strategis berawal dari penelitian yang dilakukan oleh Miles and Snow (1978) yang mengusulkan tipologi strategis yang mengklasifikasikan unit-unit bisnis ke dalam empat tipe berbeda: Prospectors, Analyzers, Defenders, and Reactors. Selanjutnya strategi bisnis yang dikembangkan oleh Porter (1980) dan manajemen strategi yang terdiri dari biaya rendah, diferensiasi, atau tipologi fokus (Parker dan Helms, 1992; Schul et al., 1995). Oleh sebab itu kemampuan pembentukan strategi UKM harus sesuai dengan orientasi strategisnya sehingga orientasi strategis berdasarkan karakteristik organisasi dapat menghasilkan kinerja UKM yang lebih baik. Penelitian ini secara umum bertujuan untuk menjelaskan mengenai pengukuran oreantasi strategi secara lebih mendalam.

\section{METODE}

Penelitian ini menggunakan pendekatan kualitatif dengan menerapkan metode penelitian kepustakaan (library research). Data yang digunakan dalam penelitian ini berupa data sekunder, yaitu buku-buku, majalah-majalah dan dokumen-dokumen tertulis. Selain itu, sumber data yang digunakan adalah data elektonik yang bersumber dari Google Scholar, Emerald Insight, Sciencedirect, SAGE.

\section{HASIL DAN PEMBAHASAN}

Penelitian studi literatur yang telah dilakukan oleh peneliti mendapatkan hasil temuan tentang perkembangan orientasi strategi jika ditinjau dari definisi dan pengukurannya, dapat dijabarkan sebagai berikut :

\section{Definisi Orientasi Strategi}

Orientasi strategis perusahaan mencerminkan arah strategis yang dilaksanakan oleh perusahaan untuk menciptakan perilaku yang tepat dalam memperoleh kinerja yang terus unggul dalam bisnis. Maka ini membutuhkan suatu definisi secara umum yang dapat diterima oleh dunia bisnis yang nantinya akan menjadi awal dalam standarisasi definisi orientasi strategi, karena Beberapa pakar dalam ilmu manajemen mendefinisikan orientasi strategi dengan cara yang berbeda-beda. Pada tabel 1 berikut ini akan memberikan uraian tentang beberapa definisi orientasi strategi sebagai berikut :

\section{Tabel 1.}

Definisi-definisi Orientasi Strategi

\begin{tabular}{cl}
\hline Sumber & \multicolumn{1}{c}{ Definisi Orientasi Strategi } \\
\hline Venkatraman & $\begin{array}{l}\text { The General pattern of various } \\
\text { means employed to archieve the } \\
\text { business goal, with a particular } \\
\text { emphasis on the business-unit } \\
\text { level of the organizational } \\
\text { hierarchy }\end{array}$ \\
\hline Gatignon & $\begin{array}{l}\text { Strategic orientation is the } \\
\text { specific approach a firm } \\
\text { and Xuereb } \\
\text { implements to create the proper } \\
\text { behaviors for superior and } \\
\text { continuous performance. }\end{array}$ \\
\hline Zhou et al. & $\begin{array}{l}\text { Strategic orientation is the } \\
\text { company's strategic direction in } \\
\text { creating the proper behavior so as } \\
\text { to achieve superior performance; }\end{array}$ \\
\hline
\end{tabular}




\begin{tabular}{|c|c|}
\hline Sumber & Definisi Orientasi Strategi \\
\hline & $\begin{array}{l}\text { both market and innovation are } \\
\text { the most strategic orientations for } \\
\text { the company to achieve superior } \\
\text { performance over a long term }\end{array}$ \\
\hline $\begin{array}{c}\text { Slater et al. } \\
2006\end{array}$ & $\begin{array}{l}\text { strategic orientation is the broad } \\
\text { strategy outline, which will be } \\
\text { completed with the details of } \\
\text { strategy content and } \\
\text { implementation. }\end{array}$ \\
\hline $\begin{array}{l}\text { Liu \& Revell } \\
2009\end{array}$ & $\begin{array}{l}\text { The strategic orientation as a } \\
\text { concept widely used in research } \\
\text { on the management of strategy, } \\
\text { entrepreneurship and marketing }\end{array}$ \\
\hline
\end{tabular}

Berdasarakan studi literatur yang bersumber dari beberapa penelitian, penulis menemukan perkembangan definisi teori orientasi strategi pertama dikemukaan oleh Miles and Snow (1978) menggunakan istilah Organization Strategy yang selanjutnya dikembangkan oleh Venkatraman (1989) menjadi strategy orientation yaitu The General pattern of various means employed to archieve the business goal, with a particular emphasis on the business-unit level of the organizational hierarchy.

Selanjutnya definisi orientasi strategi mulai dikenal dan digunakan oleh beberapa peneliti seperti Gatignon and Xuereb (1997) menyatakan bahwa Orientasi strategis adalah pendekatan spesifik yang diterapkan perusahaan untuk menciptakan perilaku yang tepat untuk kinerja yang unggul dan berkelanjutan..

Menurut Zhou et al. (2005) Orientasi strategis adalah arah strategis perusahaan dalam menciptakan perilaku yang tepat sehingga mencapai kinerja yang unggul, Slater et al. (2006) mengemukakan orientasi strategis adalah strategi yang luas, yang akan dilengkapi dengan rincian konten strategi dan implementasi strategi.

Terakhir yang menggunakan berdasarkan studi literatur yang dilakukan yaitu Liu \& Revell (2009) menekankan bahwa konsep orientasi strategi sering dipakai pada penelitian yang berfokus pada manajemen strategi, kewirausahaan dan pemasaran.

Bersumber dari beberapa perkembangan definisi orientasi strategi maka penulis menyimpulkan bahwa orientasi strategi yaitu arah strategi perusahaan untuk mencapai tujuan jangka panjang melalui penciptaan perilaku yang berorientasi pada peningkatan kinerja perusahaan.

\section{Pengukuran Orientasi Strategi}

Penggunaan orientasi strategi dalam sebuah bisnis dikatakan berhasil ketika ukuran-ukuran pencapaiannya jelas dan tepat, dengan prnulis merasa perlu untuk membahas tentang perkembangan pengukuran orientasi strategi yang digunakan oleh beberapa peneliti. Pada Tabel 2 berikut ini akan memberikan uraian tentang perkembangan pengukuran orientasi strategi yang dipakai oleh beberapa peneliti yakni sebagai berikut :

\section{Tabel 2}

\section{Pengukuran Orientasi strategi}

\begin{tabular}{|c|c|}
\hline Sumber & Dimensi Orientasi Strategi \\
\hline $\begin{array}{l}\text { Miles and } \\
\text { Snow } 1978\end{array}$ & $\begin{array}{l}\text { Prospectors } \\
\text { Defenders } \\
\text { Analyzers } \\
\text { Reactors } \\
\end{array}$ \\
\hline $\begin{array}{c}\text { Venkatraman } \\
1989\end{array}$ & $\begin{array}{l}\text { Aggressiveness, } \\
\text { Analysis, } \\
\text { Defensiveness, } \\
\text { Futurity, } \\
\text { Proactiveness and } \\
\text { Risk }\end{array}$ \\
\hline $\begin{array}{l}\text { Narver and } \\
\text { Slater } \\
1990 \\
\end{array}$ & $\begin{array}{l}\text { Customer, } \\
\text { Competitive, and } \\
\text { Technological orientations }\end{array}$ \\
\hline $\begin{array}{c}\text { Hubert } \\
\text { Gatignon and } \\
\text { Jean-Marc } \\
\text { Xuereb, } \\
1997\end{array}$ & $\begin{array}{l}\text { Customer } \\
\text { Competitor } \\
\text { Technological }\end{array}$ \\
\hline $\begin{array}{c}\text { Voss \& Voss } \\
2000\end{array}$ & $\begin{array}{l}\text { Customer, } \\
\text { Competitor and } \\
\text { Technological products }\end{array}$ \\
\hline $\begin{array}{l}\text { Antonio, } \\
\text { Emilio \& Jose } \\
2005\end{array}$ & $\begin{array}{l}\text { Technology, } \\
\text { Area of innovation, } \\
\text { Implementation flexibility, } \\
\text { Human resource system and } \\
\text { Training investment }\end{array}$ \\
\hline $\begin{array}{c}\text { Racelis } \\
2006\end{array}$ & $\begin{array}{l}\text { Marketing focus, } \\
\text { Main competence, } \\
\text { Investment strategy and } \\
\text { Innovation }\end{array}$ \\
\hline $\begin{array}{l}\text { Grinstein } \\
2008\end{array}$ & $\begin{array}{l}\text { Namely market, } \\
\text { Learning, } \\
\text { Entrepreneurship and } \\
\text { Employee orientations }\end{array}$ \\
\hline $\begin{array}{c}\text { Grawe et al. } \\
2009\end{array}$ & $\begin{array}{l}\text { Orientation of market, } \\
\text { Entrepreneurship, } \\
\text { Customer, } \\
\text { Cost, } \\
\text { Innovation, } \\
\text { Competitor, } \\
\text { Learning, } \\
\text { Employee and } \\
\text { Interaction } \\
\end{array}$ \\
\hline
\end{tabular}




\begin{tabular}{cl}
\hline Sumber & \multicolumn{1}{c}{ Dimensi Orientasi Strategi } \\
\hline Altindag et al., & Orientation of customer, \\
$2011 ;$ & Entrepreneurship, \\
Usta, & Learner and \\
2011 & Innovation \\
\hline & Orientation of team, \\
& Managerial competence, \\
Lau & Social networking, \\
2011 & Local institutional support, \\
& Low-cost orientation and \\
& Product innovation \\
\hline
\end{tabular}

Pengukuran strategi orientasi berdasarkan hasil studi literatur yang dilakukan oleh peneliti sebelumnya yaitu berawal dari oleh Miles and Snow (1978) yang dikenal dengan the strategic trilogy dengan mengklasifikasikan dalam empat dimensi yaitu Defenders, Prospectors, Analyzers dan Reactors.

Miles and Snow (1978) mengemukakan Defenders yakni memiliki domain pasar produk yang sempit, melakukan sedikit pengembangan produk baru, menghindari risiko yang tidak perlu, dan fokus pada efisiensi operasi yang ada.

Prospectors adalah organisasi yang fokus pada inovasi produk dan pasar; memaksimalkan peluang baru dan merintis inovasi untuk memenuhi kebutuhan pasar.

Analyzers adalah gabungan dari tipe prospector dan defender; menggunakan efisiensi dalam segmen pasar produk yang stabil dan berinovasi dalam pasar produk yang dinamis. Sedangkan Reactors yakni strategi yang tidak stabil karena tidak mampu merespon secara efektif terhadap lingkungan dan hanya mampu beradaptasi ketika terjadi tekanan pada lingkungan yang memaksa untuk melakukan perubahan.

Selanjutnya pengukuran orientasi strategi dikembangkan oleh Venkatraman (1989) dengan menggunakan 6 dimensi yang terdiri dari Aggressiveness, Analysis, Defensiveness, Futurity, Proactiveness dan Risk.

Aggressiveness, pelaku bisnis harus secara cerdas memiliki kemampuan untuk melibatkan sumber daya organisasi dalam melaksanakan strategi agresif dan mengejar peningkatan pangsa pasar sebagai sarana untuk mencapai profitabilitas pada unit bisnis; faktanya bahwa setiap perusahaan mencari peningkatan pangsa pasar yang lebih luas dibandingkan pesaing (Abiodun, 2009).

Analysis, mengacu pada kemampuan untuk menyelidiki secara mendalam penyebab mendasar masalah dan mengembangkan alternatif solusi terbaik sebagai cara pemecahan masalah. Hal ini berkaitan dengan konsistensi strategi dalam mengalokasi sumber daya untuk mencapaik tujuan perusahaan. Penyelarasan pengalokasian sumber daya dan competitive intelligence adalah pertimbangan dalam isu-isu penting (Abiodun \& Ibidunni, 2014).

Defensiveness, mencerminkan penekanan perusahaan pada strategi bertahan atas teknologi inti dan domain produk-pasarnya melalui penggunaan minimisasi biaya dan teknik untuk mencapai efisiensi operasional.

Futurity, Sejauh mana keputusan yang terkait dengan kemungkinan kejadian di masa yang akan datang terlibat secara serius, seperti masalah perkiraan penjualan, kemungkinan perubahan dalam preferensi pelanggan dan perubahan lingkungan. Hal ini dimanifestasikan melalui penggabungan visi perusahaan sebagai objek perhatian strategis (Stambaugh et al., 2011).

Proactiveness, Mencerminkan keterlibatan konstan perusahaan dalam mencari peluang pasar baru; penggerak pertama dalam pengenalan produk baru, sementara produk lama secara strategis ditarik dari pasar; serta menunjukkan tingkat eksperimen perusahaan dengan melihat tanggapan dari riset pemasaran yagn dilakukan (Venkatraman, 1989).

Risk, tingkat resiko dari perusahaan. Hal ini tercermin dalam pilihan dan kriteria atas keputusan alokasi sumber daya dan pola umum pengambilan keputusan. Perusahaanperusahaan yang dicirikan dengan strategi risiko tinggi memungkin melakukan trading-off dengan keuntungan lebih rendah dari yang diharapkan (Söderbom, 2012).

Kemudian Voss \& Voss (2000) menggunakan dimensi orientasi strategi ialah orientasi pelanggan, pesaing dan produk teknologi. Sementara itu, dimensi yang digunakan oleh Antonio, Emilio \& Jose (2005) adalah teknologi, bidang inovasi, fleksibilitas implementasi, sistem sumber daya manusia dan investasi pelatihan.

Dimensi pengukuran orinetasi strategi mulai berkembang dan berorientasi pada pelanggan seperti yang dikemukakan oleh Racelis (2006) bahwa pengukuran orientasi strategis terdiri dari fokus pemasaran, kompetensi utama, strategi investasi dan inovasi. Selanjutnya dimensi orientasi strategi terdiri dari orientasi pelanggan, kewirausahaan, pelajar dan inovasi (Altindag et al., 2011; Usta, 2011) menambahkan variabel pemasaran internal dan informasi manajemen. 
Kemudian, Lau (2011) menjelaskan bahwa dimensi orientasi strategis terdiri dari orientasi tim, kompetensi manajerial, jejaring sosial, dukungan kelembagaan lokal, orientasi biaya rendah dan inovasi produk.

Bersumber dari studi literatur yang dilakukan, penulis merumuskan bahwa pengukuran orientasi strategi yang sesuai bagi UKM yaitu customer, competitor, low - cost orientation, Entrepreneurship dan inovation.

Customer, untuk menciptakan nilai yang superior bagi konsumen secara terus menerus maka perusahaan harus memahami dengan baik konsumennya (Narver dan Slater, 1990). Deshpande, et al. (1993) mendefinisikan orientasi pelanggan sebagai "rangkaian keyakinan yang terlebih dahulu menempatkan minat pelanggan".

Oleh karena itu, perilaku inovatif perusahaan dalam orientasi pelanggan dapat didefinisikan sebagai perusahaan dengan kemampuan dan kemauan untuk mengidentifikasi, menganalisis, memahami, dan menjawab kebutuhan konsumen. Orientasi pelanggan juga membantu perusahaan dalam mempelajari sebagian besar masalah teknis tentang pasar dan memberikan evaluasi tentang segmen-segmen pasar, pentingnya pasar, dan tingkat pertumbuhannya.

Competitor, Orientasi pesaing dapat didefinisikan sebagai kemampuan dan kemauan untuk mengidentifikasi, menganalisis, dan merespon kembali tindakan pesaing (Narver dan Slater, 1990). Ini termasuk identifikasi dan konstruksi keunggulan kompetitif dalam hal kualitas atau fungsi tertentu dan memungkinkan perusahaan untuk memposisikan produk barunya dengan baik, serta perusahaanperusahaan inovatif yang sukses memilih jenisjenis produk baru tertentu sebagai fungsi karakteristik pasar kompetitif (Cooper, 1984). Konsekuensinya, diperlukan orientasi pesaing untuk kinerja komersial dan inovasi.

Low-cost orientation, Kepemimpinan biaya diarahkan untuk mendapatkan posisi superioritas pada pasar atas pesaing melalui biaya rendah yang dapat menghasilkan efek harga produk yang lebih rendah. Untuk mencapai tujuan tersebut, perusahaan dapat bertindak dengan mengurangi biaya produksi; meningkatkan pemanfaatan kapasitas perusahaan, mengendalikan pasokan bahan atau distribusi produk. Strategi ini serupa dengan yang diusulkan oleh Miles \& Snow (1978).
Entrepreneurship, memberi penekanan pada penciptaan baru, pencarian peluang, dan perilaku eksploratif. Orientasi kewirausahaan mengemukakan bahwa inovasi dan proaktif bersama dengan pengambilan risiko mengkarakterisasi organisasi yang berkinerja baik dengan secara konstan mengubah dinamika pasar (Miller, 1983), (Covin, 1989; Lumpkin, 1996; Wiklund, 2005), Organisasi yang berorientasi kewirausahaan mengubah dan membentuk lingkungan serta sumber daya untuk mengeksploitasi peluang yang tidak pasti. Mereka mengeksplorasi ide-ide baru dan kreatif yang dapat menyebabkan perubahan di pasar dan melakukannya secara proaktif di depan persaingan dalam mengantisipasi permintaan di masa depan. Penyesuaian dan pembentukan lingkungan yang lebih baik seharusnya memiliki efek positif pada kinerja perusahaan (Hult, 2004), (Wiklund, 2005), (Keh et al., 2007), (Wiklund, 1999). Orientasi kewirausahaan pada dasarnya adalah orientasi pertumbuhan (Covin, 2006), mengacu pada proses dan praktik yang mengarah pada "entri baru" - yaitu memulai bisnis baru, memasuki pasar baru atau memperkenalkan produk baru ke pasar yang ada (lumpkin dan dess, 1996).

Inovation, Perusahaan yang inovatif sangat berorientasi pada $\mathrm{R} \& \mathrm{D}$, proaktif dalam memperoleh teknologi baru, dan menggunakan teknologi canggih dalam pengembangan produk barunya (Cooper 1984, 1994; Kanter 1988)

\section{KESIMPULAN DAN SARAN Kesimpulan}

Berdasarkan hasil penelitian dapat disimpulkan bahwa orientasi strategi yaitu arah strategi perusahaan dalam mencapai tujuan jangka panjang melalui penciptaan perilaku yang berorientasi pada peningkatan kinerja UKM. Dalam hal pengukuran, ada banyak konsep pengukuran orientasi strategi yang dikembangkan oleh para peneliti saat ini. Namun Secara umum orientasi strategi dapat dikelempokkan menjadi tiga bagian, yaitu: market orientation, yang mencakup pengetahuan, kompetensi dan keterampilan karyawan untuk membangun hubungan yang baik dengan konsumen.

Technology orientation yang mencakup pemahaman karyawan dan manajer dalam penggunaan teknologi baru dan inovatif yang dapat meningktakan keunggulan bersaing perusahaan, Orientation to reduce the cost yang mencangkup kecenderungan untuk pengurangan 
biaya dalam bentuk stretegi kepemimpinan biaya sehingga dapat meningkatkan pangsa pasar. Ketiga elemen ini akan berinteraksi secara dinamis, serta terus menerus dan luas sehingga akan menghasilkan keunggulan bersaing bagi perusahaan.

\section{Saran}

Penelitian selanjutnya diharapkan dapat mengkaji lebih mendalam terkait faktor - faktor yang mempengaruhi orientasi kewirausahaan serta dampaknya terhadap kinerja UKM. Hal ini disebabkan orientasi strategi merupakan hal mendasar yang harus dimiliki setiap UKM sehingga dapat menjaga keberlangsungan usaha yang dijalankan.

\section{DAFTAR PUSTAKA}

Abiodun, A.J. 2009. Exploring the relationship between human personal values, strategy dimension and performance. Universitatii Bucuresti: Analele, Seria Stiinte Economice si Administrative.

Abiodun, A.J. \& Ibidunni, O.S. 2014. Strategic orientation, business level strategies, top management factor, organizational system, departmental connectivity. African Journal of Business Management, 8, 495-501.

Aghajari dan Senin. 2014. Strategic orientation and dual innovative operation strategies Implications for performance of manufacturing SMEs. Asia-Pacific Journal of Business Administration, Vol. 6 Iss 2 pp. $127-147$

Antonio, N.F., Emilio, R. \& Jose, D. 2005. Implication of perceived competitive advantage, adaptation of marketing tactics and export commitment on export performance. Journal of World Business, $45,287-300$.

Blumentritt, T. and Danis, W. 2006. Business strategy types and innovative practices. Journal of Management Issues, Vol. 18, No. 2, pp. 274-91

Cooper, Robert G. 1984. New Product Strategies: What Distinguishes the Top Performers ?. Journal of Product Innovation Management, 2 (2), 151-64.

Cooper, Robert G. 1984. The StrategyPerformance Link in Product In-novation. R\&D Management, 14 (October), 247-59.

Cooper, Robert G. 1994. New Products: The Factors that Drive Success. International Marketing Review, I (1), 60-76.
Covin J. G. and Slevin D. P. 1989. Strategic management of small firms in hostile and benign environments. Strategic Management Journal, vol.10, no. 1, pp. 7587.

Covin J. G., Green K. M., and Slevin D. P. 2006. Strategic process effects on the entrepreneurial orientation-sales growth rate relationship. Entrepreneurship Theory and Practice, vol. 30, no. 1, pp. 57-81.

Deshpande, Rohit, John U. Farley, and Frederick E. Webster. 1993. Corporate Culture, Customer Orientation, and Innovativeness in Japanese Firms: A Quadrad Analysis. Journal of Marketing, 57 (January), 23-37.

Gatignon, H. \& Xuereb, J.M. 1997. Strategic orientation of the firm and new product performance. Journal of marketing research, 77-90.

Grawe, S.J., Chen, H. \& Daugherty, P.J. 2009. The relationship between strategic orientation, service innovation and performance. International Journal of Physical Distribution \& Logistics Management, 39(4), 282-300.

Grinstein, A. 2008. The relationships between market orientation and alternative strategic orientations: A meta-analysis. European Journal of Marketing, 42(1/2), 115-134.

Kanter, Rosabeth M. 1988. When a Thousand Flowers Bloom: Structural, Collective, and Social Conditions for Innovation in Organization. in Research in Organizational Behavior, Vol 10, B. M. Staw and L. L. Cummings, eds. Greenwich, CT: JAI Press, 169-211.

Keh H. K., Nguyen T. T. M., and Ng H. P. 2007. The effects of entrepreneurial orientation and marketing information on the performance of SMEs. Journal of Business Venturing, vol. 22, no. 4, pp. 592-611.

Kumar et al. 2012. Strategic orientation, innovation patterns and performances of SMEs and large companies. Journal of Small Business and Enterprise Development. Vol. 19 No. 1, pp. 132-145

Lau, C.M. 2011. Team and organizational resources, strategic orientations and firm performance in a transitional economy. Journal of Business Research, 64(12), 1344-1351.

Lechner, Christian dan Gudmundsson, Sveinn Vidar. 2012. Entrepreneurial orientation, 
firm strategy and small firm performance. International Small Business Journal 0(0) $1-25$.

Lumpkin G. T. and Dess.G. G. 1996. Clarifying the entrepreneurial orientation construct and linking it to performance. Academy of Management Review, vol. 21, no. 1, pp. 135-172.

Miles, R. E., Snow, C. C., Meyer, A. D., \& Coleman, H. J. 1978. Organizational strategy, structure, and process. Academy of management review, 3(3), 546-562.

Narver, J.C. \& Slater, S.F. 1990. The effect of a market orientation on business profitability. The Journal of marketing, 2035.

Parker B, Helms MM. 1992. Generic strategies and firm performance in a declining industry. Management International Review, Vol. 32, No. 1, pp. 23-39

Pelham Alfred M. 1999. Influence of Environment, Strategy, and Market Orientation on Performance in Small Manufacturing Firms. Journal of Business Research 45, 33-46.

Pittino, D. and Visintin, F. 2009. Innovation and strategic types of family SMEs: A test and extension of Miles and Snow's configurational model, Journal of Enterprising Culture, Vol. 17, No. 3, pp. 257-95.

Porter, M.E. 1980. Competitive strategy: Techniques for analyzing industries and competition. New York.

Racelis, A.D. 2006. Relationship between strategic orientation and organizational performance: An exploratory study of Philippine companies. Philippine Management Review, 13(2).

Sarker, S. and Palit, M. 2015. Strategic orientation and performance of small and medium enterprises in Bangladesh. International Journal of Entrepreneurship and Small Business, Vol. 24, No. 4, pp. 572-586

Schul PL, Davis PS, Hartline MD. 1995. Strategic adaptation to extended rivalry: effects on organizational performance. Journal of Business Research, Volume 33, Issue 2, Pages 129-142

Söderbom, M. 2012. Firm size and structural change: A case study of Ethiopia. Journal of African Economies, 21(2), 126-151.

Slater, S.F., Olson, E. and Hult, G.T.M. 2006. The moderating influence of strategic orientation on the strategy formation capability-performance relationship. Strategic Management Journal, Vol. 27, pp. 1221-31.

Stambaugh, J.E., Yu, A. \& Dubinsky, A.J. 2011. Before the attack: A typology of strategies for competitive aggressiveness. Journal of Management Policy and Practice, 12(1), 49.

Usta, R. 2011. Strategic orientations enriching the effect of market orientation on company performance: Literature-based holistic model proposal. Anadolu University Journal of Social Sciences, 11(3), 65-84.

Venkatraman, N. 1989. Strategic orientation of business enterprises: The construct, dimensionality and measurement. Management science, 35(8), 942-962.

Voss, G.B. \& Voss, Z.G. 2000. Strategic orientation and firm performance in an artistic environment. Journal of marketing, 64(1), 67-83.

Xue, L. \& Revell, B.J. 2009. Which way forward for China's vegetable exports? British food journal, 111(1), 26-43.

Zhou, K.Z., Gao, G.Y., Yang, Z. \& Zhou, N. 2005. Developing strategic orientation in China: Antecedents and consequences of market and innovation orientations. Journal of business research, 58(8), 10491058 . 